\title{
“MULHERES DA FLORESTA": AS CASTANHEIRAS DO NORTE
}

FOREST WOMEN: THE NORTHERN CHESTNUT TREES

"MUJERES DE LA FLORESTA": LAS CASTAÑERAS DEL NORTE

\author{
Rita de Cássia Fraga Machado ${ }^{1}$
}

\begin{abstract}
Resumo: Para quem estuda a história das mulheres sabe o quanto ela é marcada por violências, silenciamentos, invisibilidades, lutas, antagonismos e resistências. As Mulheres da Floresta e das Águas, situadas no médio Solimões no Estado do Amazonas, sabem isso melhor do que ninguém. Suas trajetórias expressam isso, seus corpos, suas falas e suas vidas. São mulheres fortes, com uma vida marcadas por antagonismo e bonitezas: "eu só queria ter até o quinto filho, mas meu marido não deixou, tive 12 então, mas hoje estão aí 8 vivos e 4 mortos, sou feliz". Falas como essas expressam exatamente que as nossas lutas são iguais, independentemente dos nossos lugares. Minha avó teve oito filhos, mas não gostaria de ter, ainda viva nos conta que nunca pode dizer isso, pois poderia ser deixada e a vida piorar. A caminhada dessas mulheres é longa, estreita, mas "bonita, assim como as castanheiras..."
\end{abstract}

Palavras-Chaves: Mulheres da Floresta. Resistências. Lutas.

Abstract: For those who study the history of women know how much it is marked by violence, silence, invisibility, struggles, antagonisms and resistances. The Forest and Waters Women, located in the middle Solimões of the State of Amazonas, know this better than anyone else. Their trajectories express this, their bodies, their speeches and their lives. They are strong women, with a life marked by antagonism and beauty: "I only wanted to have the fifth child, but my husband did not leave, then I had 12, but today there are 8 alive and 4 dead, I am happy". Speech like these express exactly that our struggles are the same regardless of our places. My grandmother had eight children, but she would not want to have it, she tells us that she can never say that, because she could be left and life worse. The walk of these women is long, narrow, but beautiful, as are the Brazilian nut trees.

Keywords: Forest Women. Resistances. Struggles.

Resumen: Para quien estudia la historia de las mujeres sabe lo mucho que está marcada por violencias, silenciamientos, invisibilidades, luchas, antagonismos y resistencias. Las Mujeres del bosque y de las aguas, situadas en el medio Solimões en el Estado de Amazonas, lo saben mejor que nadie. Sus trayectorias expresan eso, sus cuerpos, sus palabras y sus vidas. Son mujeres fuertes, con una vida marcadas por antagonismo y bonitezas: "yo sólo quería tener hasta el quinto hijo, pero mi marido no dejó, tuve 12 entonces, pero hoy están ahí 8 vivos y 4 muertos, soy feliz". Hablas como éstas expresan exactamente que nuestras luchas son iguales, independientemente de nuestros lugares. Mi abuela tuvo ocho hijos, pero no me gustaría tener, todavía viva nos cuenta que nunca puede decir eso, pues podría dejarse y la vida

\footnotetext{
${ }^{1}$ Professora na Universidade do Estado do Amazonas- UEA. Pós-Doutoranda na Universidade do Vale do Rio dos Sinos - UNISINOS, com bolsa do Conselho de Aperfeiçoamento do Ensino Superior - PNPD/Capes.
}

Fronteiras: Revista de História | Dourados, MS | v. 19 | n. 33 | p. 131 - 146 | Jan. / Jun. 2017 
empeorar. La caminata de esas mujeres es larga, estrecha, pero "bonita, así como las castañeras ..."

Palabras clave: Mujeres del Bosque. Resistencia. Luchas.

\section{A castanheira: somos como ela}

Nós, mulheres da floresta somos como castanheiras, levamos anos para crescer, mas também não é qualquer chuva que nos derruba (Rita, 16/09/2016).

A castanheira (Bertholletia excelsa), também conhecida como castanha-do-Brasil, é a mais famosa espécie de árvore nativa da Amazônia. Árvore de grande porte, a castanheira chega a atingir até 60 metros de altura e diâmetro, na base, superior a 4 metros. A castanheira é encontrada em matas de terra firme, muitas vezes formando agrupamentos, mais ou menos extensos, conhecidos como castanhais, onde se encontram associadas a outras espécies de árvores de grande porte. Sua madeira é muito resistente, forte, e considerada bonita.

Figura 1: Castanheira

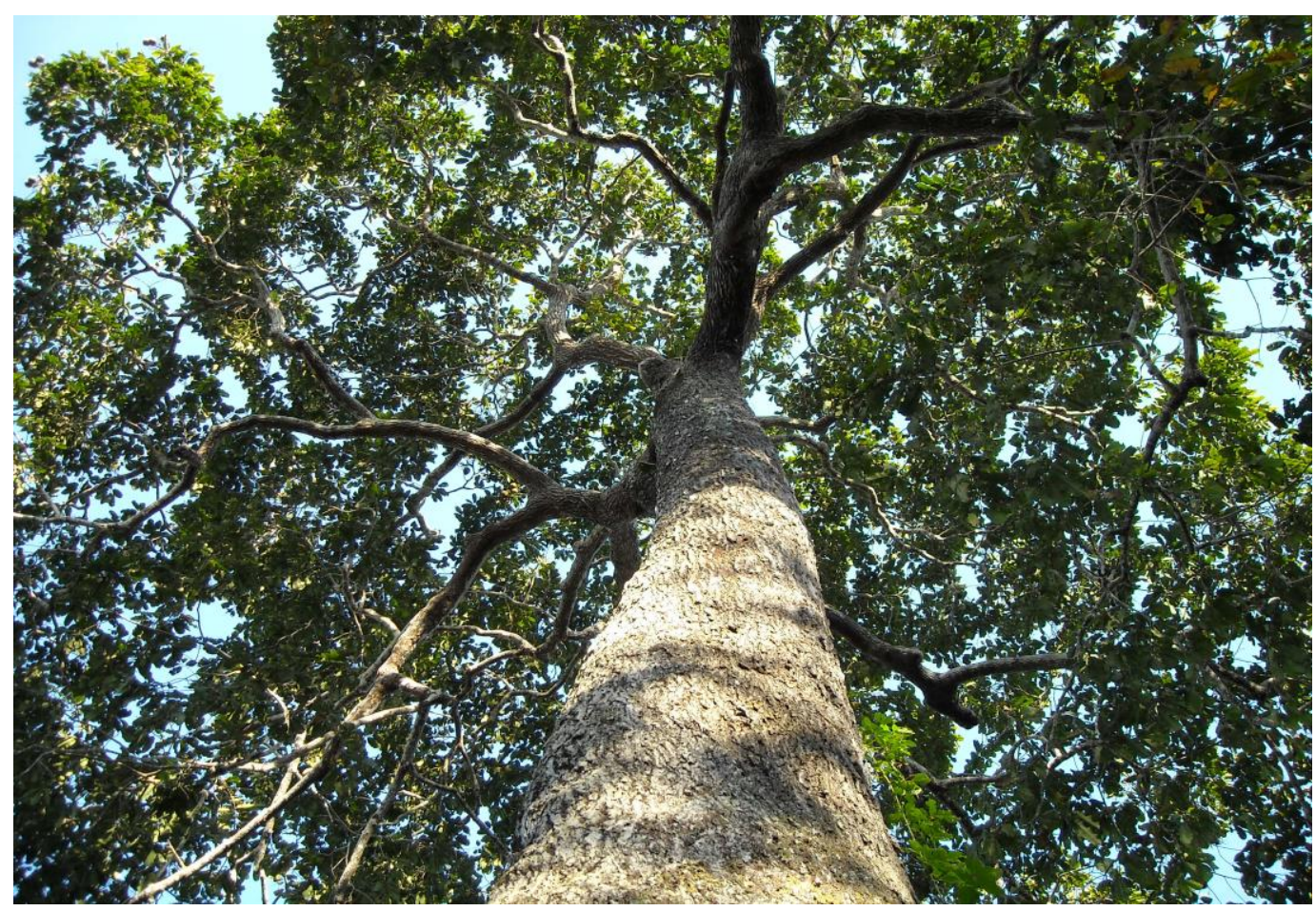

Foto: Rogério Sávio Link, 07/08/2009, Aldeia Camicuã, Boca do Acre-AM 


\section{A castanheira e as mulheres da floresta}

Para quem estuda a história das mulheres, sabe o quanto ela é marcada por violências, silenciamentos, invisibilidades, lutas, antagonismos e resistências. As mulheres da floresta e das águas, situadas no médio Solimões do Estado do Amazonas sabem isso melhor do que ninguém. Suas trajetórias expressam isso, seus corpos, suas falas e suas vidas. São mulheres fortes, com uma vida marcadas de antagonismo e bonitezas: "eu só queria ter até o quinto filho, mas meu marido não deixou, tive 12 então... mas hoje estão aí 8 vivos e 4 mortos, sou feliz" (Maria. 15/03/2015). Falas como essas expressam exatamente que as nossas lutas são iguais, independentemente dos nossos lugares. Minha avó teve oito filhos, mas não gostaria de ter; ainda viva nos conta que nunca pode dizer isso, pois poderia ser deixada e a vida piorar. A caminhada dessas mulheres é longa, estreita, mas bonita, assim como as castanheiras...

Figura 2: Encontro de formação das mulheres da floresta

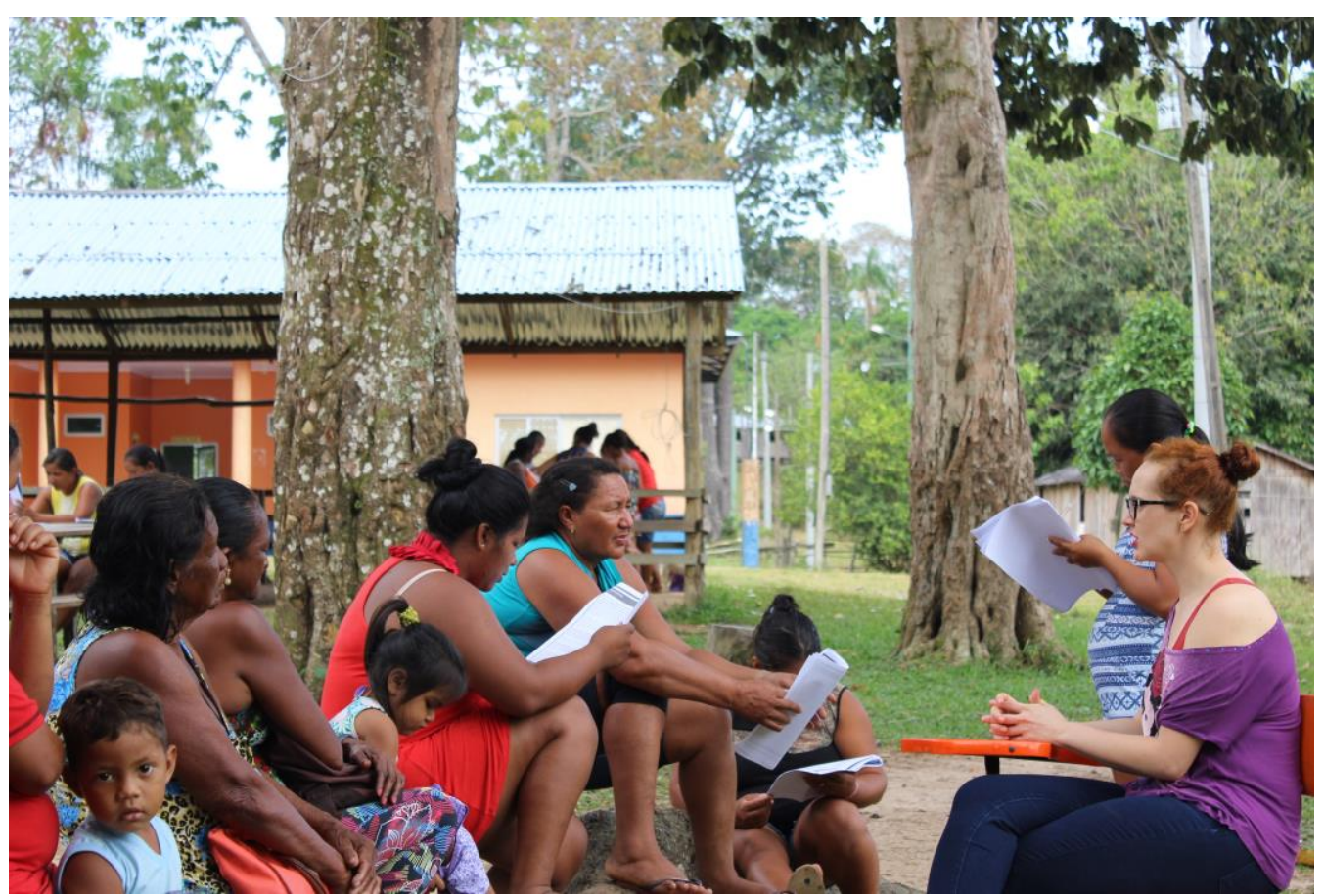

Fonte: Arquivos da pesquisadora, 16/01/2017 - Comunidade São Francisco do Arraia, Am-Tefé.

Essa fotografia (figura 2) expressa exatamente esse momento. Debaixo das castanheiras na comunidade São Francisco do Arraia, as mulheres vão compartilhando suas 
experiências de vidas. Ao relatarem suas histórias de vida, nos fazem compreender como em cada detalhe elas de fato vão se constituindo como castanheiras. "Eu, perdi três filhos dos 12 que tive, sofri muito"; "Desde os treze anos estive na roça trabalhando com meu marido"; "Nunca perdi o gosto por me perfumar, eu gosto de perfumes".

$\mathrm{Na}$ roça, as mulheres trabalham duro, mas na vida elas tecem bonito. Nos encontros de formação, estão sempre lindas, de batons, colares no pescoço, coloridas e alegres, não há um encontro que não temos uma novidade bonita delas, afinal nós mulheres temos vidas pessoais. E, assim, a cada momento da caminhada juntas elas vão resignificando suas ações. É assim que, em cada novo encontro, elas fazem questão de cantar uma canção de resistência.

Eu Vou chamar a enxada para vim se apresentar Para ser agricultor tem que ter material Eu Vou chamar a Mandioca para vim se apresentar Para ser agricultor tem que ter material Eu Vou chamar a paneiro para vim se apresentar Para ser agricultor tem que ter material Eu Vou chamar a tipiti para vim se apresentar Para ser agricultor tem que ter material Eu Vou chamar a peneira para vim se apresentar Para ser agricultor tem que ter material Eu Vou chamar o coturno para vim se apresentar

Para ser agricultor tem que ter material

Eu Vou chamar o remo para vim se apresentar

Para ser agricultor tem que ter material Dona Maria chegou, chegou, chegou, chegou com a tapioca Para fazer a farinha, farinha, farinha, farinha de tapioca Para remexer, Para remexer, Para remexer Mexer, mexer, mexer, mexer

Esses momentos constituem-se, desse modo, em um processo de aprendizagem contínuo. Essas músicas, relações, ressignificações segundo (BOURDIEU, 2002), podem contribuir para emancipar as pessoas, ajudando-as a refletir sobre situações de opressão, dominação invisível, já que a força simbólica se exerce sobre os corpos diretamente e, como que por magia, sem coerção física.

A emancipação significa um desafio para as relações de poder existentes na comunidade onde moram; representa a expansão da liberdade de escolha, ou seja, a participação, e de atuação bem como aumento da capacidade de agir das mulheres sujeitos os recursos e decisões que afetam suas vidas. É um processo que pode ajudar na superação da 
desigualdade de gênero, sempre que as mulheres reconhecerem a ideologia sexista e entenderem que essa ideologia perpetua a discriminação em relação a elas. (LEON, 2000; VASCONCELOS, 2000; KIRDAR; SILO, 2004; KEIZJER, 2005). Nesse sentido, Izidora conclui:

Bom né, ótimo assim porque pelo menos cada encontro que a gente tem assim a gente vai pegando mais conhecimento das coisas né, das coisas que a gente não sabe vai aprendendo uma com as outras e eu tou achando bom participar dos encontros né, né que é ótimo participar? (Izidora, 16/11/2016).

E é isso mesmo, a cada dia as ressignificações são muitas. A experiência de compor esse coletivo de mulheres é fundamental para quem acredita que a educação popular é em si o inédito viável: tentar precisar a compreensão da expressão da Educação Popular (EP) e de certa forma explicitar a melhor a nossa ação educativa nos confusos meandros da história presente é uma tarefa que está colocada para nós educadores e populares. E não só isso, “é um convite da filosofia a não tomarmos conceitos como absolutos". Ao refazer seus caminhos e significados a EP apresenta-se como tarefa renovada do pensamento" (GEBARA, 2016, p. 190). Assim, ao trabalharem coletivamente (figura 3), essas mulheres vão redescobrindo sua força política. Elas transformam-se em sujeitos de mudanças sociais em suas comunidades.

Figura 3: Quintal Agroecológico, sob auto-organização das Mulheres.

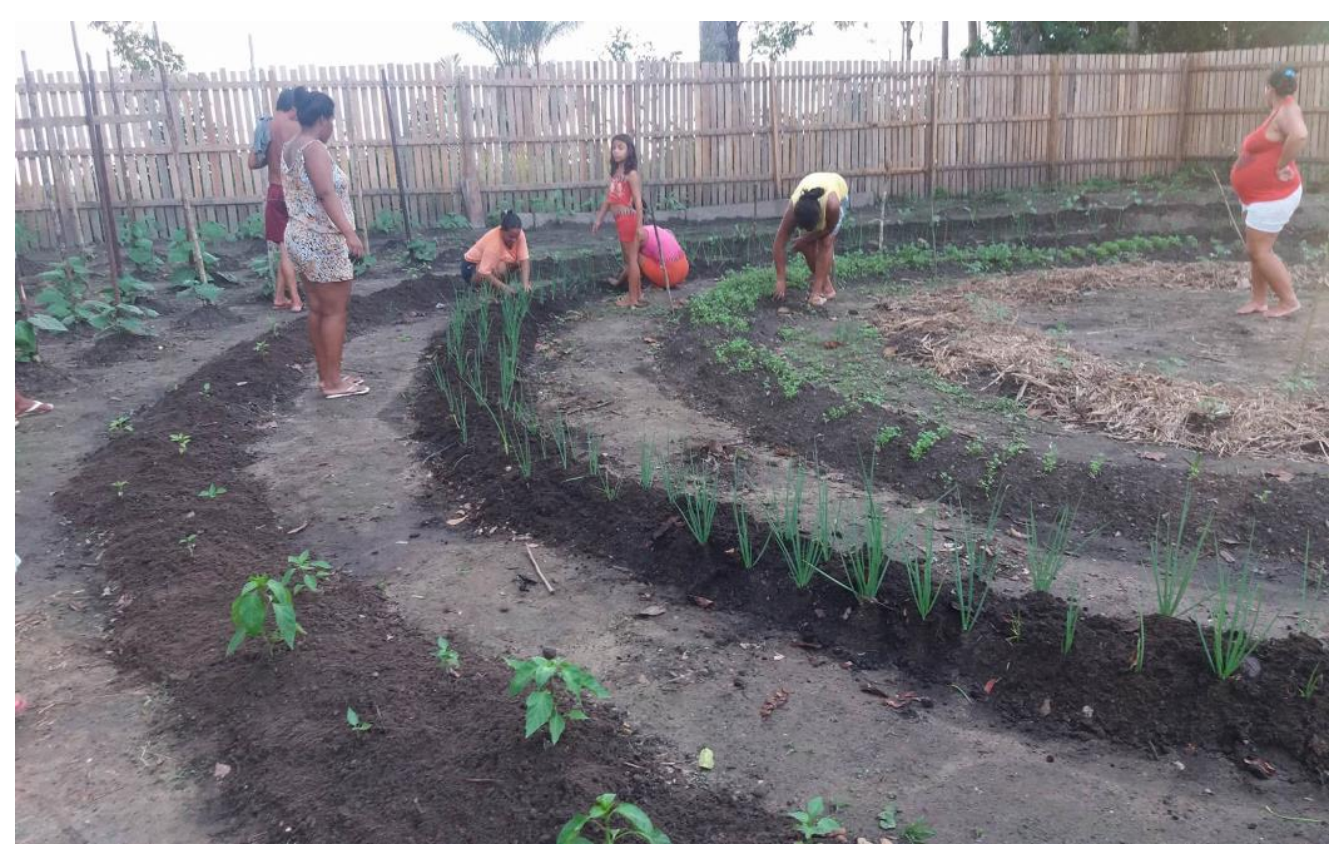

Fonte: Arquivos da pesquisadora, 2017, Comunidade São Francisco do Bauna. 
A década de 80 registrou uma ampla mobilização das mulheres rurais, com a realização de diversos encontros locais e regionais por todo o Brasil. Desde 1981, as Federações dos Trabalhadores na Agricultura passaram a incluir a representação feminina em encontros de dirigentes sindicais. Vários encontros ocorreram em diferentes municípios do Estado, preparando a participação na caravana nacional que, em 1987, congregou 12.000 participantes em Brasília, com o objetivo de pressionar os parlamentares a incluir as demandas das mulheres trabalhadoras rurais na nova legislação que estava sendo preparada (BRUMER, 1993). Porque se entende - Via Campesina - que a coletivação da agricultura para as mulheres é de extrema importância para diminuir a desigualdade social

Segundo Krúspukaya:

A coletivização da agricultura tem sido uma singular importância para a emancipação da mulher. Desde o começo de suas atividades, Lenin via na coletivização via de reestruturação da agricultura sob as bases socialistas. (...) Lenin cita as palavras de Marx: depois da expropriação dos expropriadores, quer dizer, após ter sido arrebentada a terra dos latifúndios e as fábricas dos capitalistas, chegará a hora da cooperação (agrupamento NK.) dos trabalhadores (SIC) livres, a hora de sua posse comunal (coletiva, esclarece Lenin) da terra e dos meios de produção por eles (SIC) produzido (KRÚSPUKAYA, 1933, XII).

Portanto, essa coletivização da agricultura, vista sob a forma comunitária de viver das mulheres, se apresenta como emancipação. Ao produzir coletivamente elas socializam coletivamente fazendo com que todas em sua volta tenham o que comer. "Se tem açaí na comunidade, todas comem açaí, se se pesca um peixe todas teremos peixe para o almoço" (entrevista, D).

\section{A luta por educação e as mulheres da floresta ${ }^{2}$}

Não há educação formal de qualidade e em quantidade nas comunidades tradicionais as quais realizamos esta pesquisa. A educação dos povos da floresta historicamente tem se caracterizada em meio a processos de luta e resistência em torno dos seus territórios e modos de vida. É difícil escutarmos de uma comunidade que há escola e escola de qualidade, que há saúde e saúde de qualidade. O povo dessas comunidades, além de lutar por todas as questões,

\footnotetext{
${ }^{2}$ Fragmentos desse texto foram publicados em um Dossiê sobre a Educação e Democracia, na UFFS. 
a nosso ver, faz parte de um estado democrático de direito que luta pela preservação e conservação da floresta porque entende que a floresta é o lugar de produção econômica e moradia das populações extrativistas.

É da floresta e das águas que olham com esperança para o Brasil. Mesmo com todas as ausências e a escassez, estas populações não desacreditam que se possa avançar e avançar no reconhecimento e no respeito a toda a sua diversidade e com educação de qualidade no empenho de eliminar as desigualdades sociais, assegurando às populações extrativistas que tenham melhorias e seus direitos garantidos.

Com base nas pesquisas que estamos realizando, estamos entendendo que as mulheres são sujeitos sociais. A luta pela terra, pela floresta e pela água, tendo como centralidade a valorização das populações extrativistas, realiza-se, em espírito comunitário, o fortalecimento de seus laços familiares e a prática do bem viver. É muito forte nessas populações a participação comunitária como elemento de mediação pedagógica para sua emancipação.

É, nesse contexto, que o CNS passa a ser intitulado Conselho Nacional de Populações Extrativistas, abrangendo a luta de todos os povos da floresta e das águas. Essa luta continua a centrar-se na educação. A trajetória e o reconhecimento desse processo foi o que garantiu a conquista de escolas em muitas comunidades das reservas onde estão localizadas. Nesse movimento, ressalta-se a presença de muitos parceiros que se juntam à causa. $\mathrm{Na}$ possibilidade de essas comunidades terem o direito à educação, destacamos que um cenário de educação de qualidade está muito distante. O sonho da "boa" escola, da professora que ensine com compromisso "técnico e político" (SAVIANI, 1998), da biblioteca, bem como de melhores condições da escola já existente foram e são reivindicações constantes desta população que entende que a escola ainda é o lugar de emancipação. Nas andanças pela floresta, escutamos as mulheres lutando e reivindicando educação de qualidade para suas crianças:

\footnotetext{
"professora, precisamos de escola para nossos filhos" "no dia 07 de setembro queremos da pátria uma professora"

"a escola deu duas aulas ano passado"

"Professora, não aguentamos mais, estamos indo embora"

(Entrevista Mulheres da Floresta)
}

A autora Martha Nussbau afirma que as mulheres são tidas como pessoas de segunda categoria no mundo. Sua afirmação se sustenta porque as mulheres são mais mal alimentadas; 
têm menor nível de saúde; são mais vulneráveis ao abuso sexual, à violência física; são menos alfabetizadas do que os homens; ganham menos que os homens e sofrem mais violência e assédio em espaços de trabalho do que os homens além de menos direito de ir e vir (NUSSBAU, 2002, p. 102).

Nesse mesmo sentido, Sandra Duarte de Souza pontua:

Um bilhão de mulheres, ou uma em cada três do planeta já foram espancadas, forçadas a ter relações sexuais ou submetidas a algum tipo de abuso. 50\% das latino-americanas experimentaram algum tipo de violência. No Brasil, estima-se que a cada 15 segundos uma mulher é agredida, normalmente em seu lar, por uma pessoa com quem mantém relações afetivas (SOUZA, 2009, p. 42-43).

Dessa forma, podemos afirmar que os direitos não têm sido igualitários para ambos os sexos, deixando as mulheres em desvantagem, incluído o campo da Educação Formal: “de todas maneras, las desiguales circunstancias sociales y políticas dan a las mujeres capacidades humanas desiguales" (CASTRO; OLIVEIRA, 2014). Segundo Ivone Gebara (1997), "às mulheres e ao povo pobre restavam o conhecimento empírico, baseado na experiência cotidiana e que não era reconhecido como verdadeiro". A mesma autora segue afirmando que

Pobres e mulheres eram associados a níveis mais baixos de abstração, de ciência e sabedoria. A hierarquização do saber corresponde à própria hierarquização social. Uma hierarquização fundada na exclusão das maiorias em favor de uma elite masculina detentora do poder e do saber. Ela se refere à questão das classes sociais e também de gênero (GEBARA, 1997, p. 34).

Isso posto, compreendemos que, entre a beleza da floresta e a diversidade do povo que nela habita, as mulheres estão em desvantagem.

\section{As ressignificações}

Sabemos da importância que a resistência e as ressignificações possuem na vida dessas mulheres, porque a partir das possibilidades elas podem representar e mudar suas vidas avançando o que elas chamam de "viver bem". São mulheres que no processo estão descobrindo a importância da sua participação na democratização das suas relações. Descobrirem-se castanheiras também tem se expressado no esforço delas em estar presente em todos os espaços de decisões, majoritariamente de homens e também em espaços de 
formação dizendo a "sua palavra" como foi a participação delas na I Caravana de Agroecologia e Mulheres que aconteceu em Parintins, em 2017.

Isso tudo nos possibilita entender que são mulheres de muita força que lutam por um futuro diferente para si e para suas filhas. Como diz Francisca, "eu sonho um futuro melhor que o meu para meus filhos" (Francisca, 16/03/2016).

Pensar trabalho e educação enquanto espaços democráticos para as mulheres da floresta é um desafio urgente para o fortalecimento das comunidades. O trabalho é a manifestação vital do ser humano, "a forma histórica da atividade humana" (MANACORDA, 2010, p. 47). O ser humano se diferencia do animal por sua capacidade de projetar suas atividades; compreende sua atividade como uma esfera própria, diferenciada de sua própria existência. Ao contrário dos animais, as pessoas fazem da sua atividade um resultado de seu querer, de sua consciência. É precisamente este querer que está bloqueado na sociedade de classes, onde o conteúdo do trabalho é determinado "de fora", à revelia da pessoa que trabalha.

Antes do advento da sociedade de classes, o processo educativo coincidia com a própria vida, isto é, os seres humanos se educavam no processo de trabalho e de existência. Não existiam espaços ou tempos específicos para aprender; as pessoas aprendiam pela experiência, imersos na práxis social ${ }^{3}$. Podemos dizer, assim, que as novas gerações aprendiam a trabalhar trabalhando.

Assim, configura-se como desafio o processo de busca por emancipação e participação dessas mulheres. O projeto que nasce após a criação do CNS estabelece, segundo Ferreira (2010), “a ação educativa como estratégica de fortalecimento do movimento". Constitui, segundo o autor, uma estratégia de elevar as condições de alfabetização e da conscientização política do movimento. Destacamos também a elevada participação comunitária dessas mulheres ${ }^{4}$ na manutenção da sua vida e na construção do seu modo de vida, no estímulo a sua

\footnotetext{
${ }^{3}$ Para apreender toda a força dessa passagem, é importante atentarmos para a influência exercida por Antonio Gramsci (2001) sobre Saviani. Em seus Cadernos do cárcere, escrevendo sobre o papel do senso comum na transformação da história, Gramsci lembra que os trabalhadores têm um conhecimento do mundo na medida em que o transformam, porém o que eles não têm é uma consciência teórica deste fato. A esse saber oriundo da atividade vital Gramsci chama senso comum. Nesse sentido, a práxis dos trabalhadores forma sua consciência prática que, implícita em sua ação, os une enquanto classe que transforma a natureza.

${ }^{4}$ Estas reflexões vêm aparecendo no projeto de iniciação cientifica da aula de Zila Castro: "A participação das mulheres da floresta no fortalecimento da ação comunitária", coordenado pela Prof. ${ }^{\text {a }}$ Dr. ${ }^{\text {a }}$ Rita de Cássia Fraga Machado, professora da Universidade do Estado do Amazonas - UEA.
} 
emancipação. Este espaço é muito significativo e constitui, a nosso ver, um lugar de resistência, luta e esperança nas manifestações dessas populações.

O esforço de análise dentro de uma perspectiva imanente ontocriativa, à luz dos povos da Floresta, não só é pertinente, como de crucial importância para reafirmar a pertinência das contribuições de Marx e Engels e demais marxistas que seguiram seu legado para a própria proposta das comunidades, assim como os trabalhos do próprio Frigotto, Acácia Kuenzer, Dermeval Saviani, Lessa, Manacorda e Heleieth Saffioti sobre a concepção ontológica de educação e trabalho são de enorme relevância, pois o trabalho em que este povo acredita é o da extração para sobreviver.

Propondo o trabalho necessário como forma de organização, também reconhecemos as dificuldades, por exemplo, da ciência, da tecnologia, do avanço das forças produtivas, do papel da escola e dos processos educativos no interior das relações sociais capitalistas dentro de um povo que se quer e é diferente.

Os ganhos alcançados com o trabalho enquanto valor de uso para a sociedade são imensos; o maior e mais fundamental deles é o da solidariedade e da produção livre. Isso tudo criaria novos valores, novas formas de produção, novas formas de relacionamento, ou seja, a humanização que nesta particularidade se fortalece pelo espírito comunitário.

No título do parágrafo do livro A Educação para Além do Capital de Mészáros (2008), podemos encontrar o sentido e as questões para a proposta que fazemos. A educação para além do capital, segundo Jinkings, na apresentação do livro,

[...] ensina que pensar a sociedade tendo como parâmetro o ser humano exige a superação da lógica desumanizadora do capital, que tem no individualismo, no lucro e na competição seus fundamentos. Que educar é segundo Gramsci - colocar fim à separação entre homo faber e homo sapiens; é resgatar o sentido estruturante da educação e da sua relação com o trabalho, as suas possibilidades criativas emancipatórias (MÉSZÁROS, 2008, p. 9).

Para desenvolver o tema, Mészáros (2008) utiliza-se de três citações que, no decorrer da temática, sintetizam a centralidade da reflexão que pretendemos propor neste estudo. $\mathrm{O}$ tema central da reflexão de Mészáros gira em torno da alienação da educação, na medida em que ela é apresentada como forma de instauração e manutenção do sistema capitalista desconsiderando a cultura e a materialidade de uma comunidade. Várias passagens do texto apontam que a educação para o mercado não é meio de instruir a vida. A educação, que 
deveria ser fator de transformação social, contra-hegemônica, desalienante, passa a ter suas mudanças limitadas apenas para trazer crescimento econômico ao sistema, dentro de seus valores.

Na passagem A incorrigível lógica do capital e seu impacto sobre a educação, o autor resgata concepções filosóficas já produzidas acerca da educação e as situa no âmbito da história, mostrando suas limitações e seu comprometimento, em última instância, com os limites impostos pela sociedade do capital.

Não surpreende, portanto, que mesmo as mais nobres utopias educacionais, anteriormente formuladas do ponto de vista do capital, tivessem de permanecer estritamente dentro dos limites da perpetuação do domínio do capital como modo de reprodução sócio-metabólica. (...)

A razão para o fracasso de todos os esforços anteriores, e que se destinavam a instituir grandes mudanças na sociedade por meio de reformas educacionais lúcidas, reconciliadas com o ponto de vista do capital, consistia - e ainda consiste - no fato de as determinações fundamentais do sistema do capital serem irreformáveis. (...) o capital é irreformável porque pela sua própria natureza, como totalidade reguladora sistêmica, é totalmente incorrigível (MÉSZÁROS, 2008, p. 26-27, destaque nosso).

Trata-se, portanto, da contínua necessidade de autoexpansão do sistema capitalista e de acumulação para a qual se deve produzir e reproduzir ininterruptamente as condições objetivas de sua conservação.

O impacto da incorrigível lógica do capital sobre a educação tem sido grande ao longo do desenvolvimento do sistema. (...) É por isso que hoje o sentido da mudança educacional radical não pode ser senão o rasgar da camisa de força da lógica incorrigível do sistema: perseguir de modo planejado e consistente uma estratégia de rompimento do controle exercido pelo capital, com todos os meios disponíveis, bem como todos os meios ainda a ser inventados, e que tenham o mesmo espírito (MÉSZÁROS, 2008, p. 35).

No item As soluções não podem ser apenas formais: elas devem ser essenciais, o autor, em busca da educação emancipadora, propõe que a superação da ordem do capital não significa apenas sua negação e, sim, a construção de uma nova ordem capaz de sustentar a si própria, e é por meio da educação que se pode produzir esta nova concepção, como que "antecipando" uma nova forma de metabolismo social e orientando os meios para a sua execução.

Esse processo de antecipação deve criar uma espécie de "contrainternalização" (ou contraconsciência) que quebre o círculo de reprodução do capital, de maneira concreta. Isso 
significa criar uma forma de consciência social que liberte dos limites impostos pelo sistema, de modo a tornar os indivíduos capazes de fazer do processo de aprendizagem "a sua própria vida”. Mészáros (2008, p. 59) diz ainda que é apenas nesse sentido amplo de educação que a educação formal, institucionalizada, pode contribuir para a superação do capital, realizando suas "necessárias aspirações emancipadoras", o que requer "um progressivo e consciente intercâmbio com processos de educação abrangentes como 'a nossa própria vida'”.

Portanto, a educação tem sentido quando proposta como transcendência positiva da autoalienação do trabalho, e neste sentido tem por tarefa "contribuir para que a superação do capital seja feita de forma total e não mais parcial, ou particular, como nas estratégias reformistas". É contra as determinações sistêmicas do capital que ela deve combater, e seu papel é "soberano", "tanto para a elaboração de estratégias apropriadas e adequadas para mudar as condições objetivas de reprodução, como para a automudança consciente dos indivíduos chamados a concretizar a criação de uma ordem social metabólica radicalmente diferente" (MÉSZÁROS, 2008, p. 65). A esse respeito, dois conceitos principais devem ser postos em primeiro plano: a universalização da educação e a universalização do trabalho como atividade humana autorrealizadora. De fato, nenhuma das duas é viável sem a outra.

Nesse sentido, a Educação Necessária: para ir além configura-se nesta relação, a relação trabalho-educação, com a perspectiva de criar e desenvolver uma proposta educativa para as mulheres da floresta que, ainda dentro desta sociedade capitalista, possa ir, por meio da formação, articulando a escolarização, o conhecimento técnico e as políticas públicas necessárias para a reprodução material da vida visando, nesta proposta, uma ordem diferente, o que se faz urgente e necessário.

Esse debate é retomado no item cinco, Educação e sociedade de classes, dessa vez para demonstrar como a educação se relaciona dialeticamente com o trabalho. Saviani (2005) argumenta que, diferentemente dos animais que se adaptam à natureza, portanto têm sua existência garantida pela natureza, o ser humano precisa adaptar a natureza para sobreviver, precisa transformá-la adaptando-a a si. $\mathrm{O}$ ato de transformar a natureza mediante o uso de determinados instrumentos visando garantir a produção da existência é o ato especificamente humano ao qual chamamos trabalho. Ora, dado que nossa existência não é garantida pela natureza, que precisamos adaptá-la para sobreviver, o processo pelo qual aprendemos a agir sobre a natureza com tal finalidade é parte indissociável do processo de trabalho. Precisamos aprender a trabalhar e, sabendo isso, transmitir às novas gerações esse saber: "eis por que 
também se diz que a educação é uma atividade especificamente humana, sendo o homem [sic] produto da educação" (SAVANI, 2005, p. 247). Para o mesmo autor,

A educação coincidia com o próprio processo de existência. Era a própria vida. Isso quer dizer que o princípio de que "educação é vida", enunciado teoricamente muitos séculos depois pelo movimento da Escola Nova, nas comunidades primitivas, era verdade prática. No próprio ato de viver os homens se educavam e educavam as novas gerações (SAVANI, 2005, p. 247).

Não existe escola quando não existem classes sociais! A escola é filha da propriedade privada e do advento das classes sociais. Surgiu com a apropriação privada da terra, destaca o autor. Saviani (2005) define as classes a partir da propriedade dos meios de produção, o que historicamente ${ }^{5}$ se deu a partir da divisão da sociedade em duas classes fundamentais: de um lado, a classe dos proprietários de terra, de outro a classe dos não proprietários; de um lado a classe daqueles que não precisam trabalhar para viver, de outro a classe daqueles que precisam entregar o fruto de seu trabalho para a minoria proprietária. A escola, entendida como um espaço especificamente destinado à atividade educativa nasce junto com a sociedade de classes para servir a classe dos proprietários. Daí o significado da expressão escola em grego: "lugar do ócio" (SAVIANI, 2005, p. 248).

Evidentemente, em uma sociedade fundada sobre a divisão fundamental entre proprietários/as e não proprietários/as, a educação deveria também reproduzir certa divisão, de modo que introduzimos a dualidade educacional: uma educação teórica para as classes dominantes, fornecida nas escolas; uma educação prática para as classes dominadas, educação que, a exemplo da anterior, é dispensada em meio ao próprio processo de trabalho. Temos aqui um elemento fundamental da reflexão marxista sobre educação; a sociedade classista impõe uma educação dualista em dois sentidos: dualista porque promove uma separação física, pois as classes dominantes vão aprender em escolas, e as classes dominadas vão aprender no trabalho; dualista porque implica uma divisão de saberes - aos primeiros uma educação teórica, para o pensar, aos segundos uma educação prática, para o fazer.

\footnotetext{
5 Conforme Ciro Flamarion Cardoso (1990), por volta do III milênio antes de Cristo, essa separação se consolidou na região entre os rios Tigre e Eufrates. Sumérios, acádios, assírios, caldeus e babilônios são alguns dos povos que teriam feito essa transição da propriedade privada de terras e de rebanhos na região da Mesopotâmia.
} 
Essa dualidade é encontrada em todas as sociedades classistas, assumindo características particulares em determinados tempos e espaços e afirmando-se como estrutura educacional nas sociedades classistas. Saviani salta sobre essas variações, chegando à educação no moderno capitalismo industrial que, diferentemente das sociedades classistas que o antecederam, apresenta uma tendência à expansão do sistema escolar, à sua universalização, ao menos enquanto meta proclamada. Como podemos explicar isso?

O desenvolvimento das forças produtivas exige dos/as trabalhadores/as alguns conhecimentos que não podem ser aprendidos pela simples prática; exige alguma forma de escolarização. Ao mesmo tempo, a forma política que toma a dominação burguesa exige a escolarização das classes dominadas; esse é o caso da alfabetização como precondição para o exercício da cidadania e para que o trabalhador/a possa vender "livremente" sua força de trabalho conforme os padrões contratuais de uma sociedade liberal. Temos então que, sob o capitalismo, a escola é portadora de uma contradição fundamental: por um lado, o sistema precisa estender a escolarização para a classe trabalhadora; de outro, a socialização dos conhecimentos historicamente produzidos entra em choque com o funcionamento do sistema, baseado na apropriação privada de trabalho e de saberes ${ }^{6}$.

O desenvolvimento da educação e, especificamente, da escola pública entra em contradição com as exigências inerentes à sociedade de classes de tipo capitalista. Esta, ao mesmo tempo em que exige a universalização da forma escolar de educação, não a pode realizar plenamente, porque isso implicaria a sua própria superação (SAVIANI, 2005, p. 257).

Nessa contradição, podemos pensar a história da educação escolar sob a tutela do capital, os avanços e recuos de sua ação educativa, a dificuldade que a burguesia tem de atender até mesmo as reivindicações mais elementares em matéria educacional, sem entrar em contradição consigo mesma. Saviani (2005) propõe que é sobre essa contradição que devem agir os educadores que pretendem pensar e propor uma educação na perspectiva da superação da sociedade capitalista. A luta pela escola pública é a luta contra a apropriação privada de conhecimentos, luta que, em última instância, colocaria em xeque a própria estrutura de organização da sociedade capitalista. Nas palavras de Saviani:

\footnotetext{
${ }^{6}$ Aníbal Ponce (2005) já havia aludido a essa contradição na obra fundadora da reflexão marxista sobre educação em nosso continente.
}

Fronteiras: Revista de História | Dourados, MS |v. 19 | n. 33 | p. 131 - 146| Jan. / Jun. 2017 
[...] o enfrentamento dos desafios postos à educação pública pela sociedade de classes passa, do ponto de vista da pedagogia histórico-crítica, pela luta por uma escola pública que garanta aos trabalhadores um ensino da melhor qualidade possível nas condições históricas atuais, entendida como um componente na luta mais ampla pela superação da própria sociedade de classes (SAVIANI, 2005, p. 271).

Conclusivamente, podemos dizer que a Educação necessária: para ir além entende que a luta pela escola pública de qualidade levada a cabo pelos trabalhadores/ras da floresta pode ser articulada à luta organizada pela superação do próprio capitalismo. Aliás, esta é a forma mais consequente de lutar pela escola pública, pois a universalização de uma escolarização de qualidade articulada com a universalização do trabalho colocaria em xeque uma das estruturas básicas do sistema social vigente: a apropriação privada de conhecimentos, engendrada pela apropriação privada do trabalho e sua concentração no grande capital.

\section{Referências}

BOURDIEU, Pierre. A dominação masculina. 2. ed. Rio de Janeiro: Bertrand do Brasil, 2002.

BRUMER, Anita; GIACOBBO, Elisa Olívia. A mulher na pequena agricultura modernizada. Humanas, Revista do Instituto de Filosofia e Ciências Humanas da Universidade Federal do Rio Grande do Sul, v. 16, n. 1, p. 139-156, jan./jun. 1993.

CASTRO. Amanda Motta; OLIVEIRA, K. L. (Org.). Desigualdades de gênero e as trajetórias latino-Americanas: Reconhecimento, dignidade e esperança. $1^{\mathrm{a}}$. ed. São Leopoldo: EST, 2014.

GEBARA. Ivone. Educação Popular: a ressignificação das expressões In: CASTRO, Amanda Motta; MACHADO, Rita de Cassia. Estudos Feministas, mulheres e Educação Popular. 1. ed. Curitiba: CRV, 2016.

GEBARA. Ivone. Teologia Ecofeminista. São Paulo: Olho D”Agua, 1997.

KEIJZER, Benno. Los discursos de la educación y participación en salud: de la evangelización sanitaria al empoderamiento. In: MINAYO, Maria Cecília; COIMBRA JÚNIOR, Carlos (Orgs.). Críticas e atuantes: ciências sociais e humanas em saúde na América Latina. Rio de Janeiro: FIOCRUZ, 2005. p. 441-460.

KIRDAR, Uner; SILO, Leonard. El gran desafio de nuestro tiempo es llevar la gente desde el empobrecimento al empoderamiento. Disponível em: www.paho.org/generoysalud. Acesso em: mar. 2004.

KOSIK, K. Dialética do concreto. 2. ed. Rio de Janeiro: Paz e Terra, 1976. 
LEON, Magdalena. Empoderamiento: relaciones de las mujeres con el poder. Revista Estudos Feministas, v. 8, n. 2, p. 191-205, 2000.

KRUPSKAYA, N. LENIN. LEON. Extraído do prefácio a "A emancipação da mulher". In: Escritos de V. I. Lenin (1933).

MANACORDA, Mario Alighiero. Marx e a pedagogia moderna. Campinas, SP: Alínea, 2010.

MÉSZÁROS, István. A educação para além do capital. 2. ed. São Paulo: Boitempo, 2008.

NUSSBAUM, Martha. Las mujeres y el desarrollo humano. Barcelona: Herder. 2000.

SAVIANI, D. Pedagogia histórico-crítica: primeiras aproximações. 10. ed. Campinas: Autores Associados, 2005.

SOUZA. Sandra Duarte de. A casa, as mulheres e a igreja: Gênero e a religião no contexto familiar. São Paulo: Fonte Editorial, 2009.

VASCONCELOS, Eymar M. Reinvenção da cidadania: empowerment no campo da saúde mental. In: AMARANTE, Paulo (Org.). Ensaios: subjetividade, saúde mental, sociedade. Rio de Janeiro: FIOCRUZ, 2000. p. 169-194. 